\title{
Non-invasive assessment of left ventricular function after correction of severe aortic regurgitation
}

\author{
A. Venco ${ }^{1}$, M. G. St John Sutton, D. G. Gibson, and D. J. Brown \\ From the Department of Cardiology, Brompton Hospital, London
}

Twenty patients were studied with simultaneous left ventricular cavity echocardiograms and apex cardiograms during the first two weeks after correction of severe aortic regurgitation. Endocardial echoes and apex cardiograms were digitized, so that left ventricular dimensions, their rates of change, and echo dimension-apex cardiogram relations could be studied. After aortic valve replacement, there was an early reduction in enddiastolic dimension, within 2 days, from $7 \cdot 0 \pm 0 \cdot 8 \mathrm{~cm}$ to $5 \cdot 7 \pm 1 \cdot 0 \mathrm{~cm}(P<0 \cdot 001)$, while peak normalized

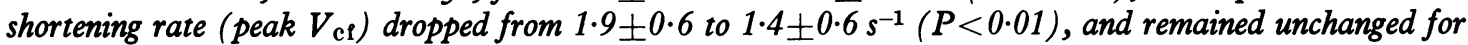
the remainder of the study. Immediately after operation, striking abnormalities of isovolumic contraction and, to a lesser extent, of early relaxation, could be seen, which regressed over 4 to 7 days, except in 2 patients who developed a low output state. These changes in left ventricular dimension, $V_{\mathrm{ct}}$, and isovolumic contraction could not have been described by any single 'measure' of left ventricular function.

Although correction of aortic regurgitation can now be undertaken with low mortality, using either homograft or mechanical prostheses, there is still doubt as to the extent to which left ventricular disorder persists after operation. In order to study this question, several approaches have been used, including measurement of haemodynamic variables in the immediate postoperative period (Carey and Plested, 1972; Uhrenholdt et al., 1973), formal postoperative cardiac catheterization and angiography (Gault et al., 1970), measurement of systolic time intervals (Seabra-Gomez, Sutton, and Parker, 1974), cineangiographic observations of the movement of epicardial clips (McDonald, 1972), and echocardiographic assessment of left ventricular transverse dimensions (Burggraf and Craige, 1975). In spite of these studies, however, the nature of the left ventricular disorder remains uncertain, and there is little knowledge of sequential changes in individual patients, particularly in the immediate postoperative period. The present investigation, based on echocardiography, was designed to provide information about cavity dimensions, peak rates of wall movement, and contraction pattern in the period immediately after operation in a group of patients

Received 10 May 1976.

'Present address: Medica Clinica II, Universita di Pavia, Pavia, Italy. undergoing aortic valve replacement for free aortic regurgitation.

\section{Patients and methods}

Twenty patients were studied, 15 men and 5 women, age range 18 to 61 , average 35.8 years. All of them required aortic valve replacement for severe aortic regurgitation; though 4 had additional mitral valve replacement and 1 mitral valve repair, the dominant lesion in all was aortic. Clinical and operative data are given in Table 1.

Simultaneous echocardiograms and apex cardiograms were recorded in the immediate postoperative period. In 12 patients, a single examination was performed a mean of 7 days after operation, and in 8 multiple examinations were made, the earliest at a mean of 2 days and the latest 9 days after valve replacement. Echocardiograms were recorded with a Smith Kline Ekoline 20 ultrasonoscope connected to either a Cambridge or a Honeywell 1856 stripchart recorder, using a $2.25 \mathrm{MHz} 1.25 \mathrm{~cm}$ transducer. Clear continuous echoes of the endocardium of the left side of the septum and the posterior wall were obtained. Apex cardiograms were recorded with a Cambridge Scientific Instruments transducer with a time constant of $4 \mathrm{sec}$ and a lower frequency limit of $0.04 \mathrm{~Hz}$. All recordings were made photo- 
TABLE 1 Clinical details

\begin{tabular}{|c|c|c|c|c|c|c|c|}
\hline Case No. & Age (y) & Sex & Aetiology & Additional & Bypass (min) & Hypothermia $\left({ }^{\circ} \mathrm{C}\right)$ & Coronary perfusion \\
\hline 1 & 29 & $\mathbf{M}$ & Cong & Coarctn & 75 & 34 & $\mathbf{R}+\mathbf{L}$ \\
\hline 2 & 40 & $\mathbf{F}$ & $\mathbf{R h}$ & - & 90 & 26 & - \\
\hline 3 & 40 & $\mathbf{M}$ & $?$ & - & 133 & 30 & $\mathbf{R}+\mathbf{L}$ \\
\hline 4 & 32 & $\mathbf{M}$ & Cong & - & 60 & 34 & $\mathbf{R}+\mathbf{L}$ \\
\hline 5 & 39 & $\mathbf{M}$ & $\mathbf{R h}$ & 一 & 105 & 34 & $\mathbf{R}+\mathbf{L}$ \\
\hline 6 & 61 & $\mathbf{M}$ & $\mathrm{Rh}$ & MVR & 95 & 30 & $\mathbf{R}+\mathbf{L}$ \\
\hline 7 & 29 & $\mathrm{~F}$ & $\mathrm{Rh}$ & 一 & 55 & 34 & $\mathbf{R}+\mathbf{L}$ \\
\hline 8 & 50 & $\mathbf{F}$ & $\mathrm{Rh}$ & - & 95 & 30 & $\mathbf{R}+\mathbf{L}$ \\
\hline 9 & 30 & $\mathbf{M}$ & $?$ & - & 80 & 33 & $\mathbf{R}+\mathrm{L}$ \\
\hline 10 & 52 & $\mathrm{~F}$ & Rh & 一 & 66 & 32 & $\mathrm{R}+\mathrm{L}$ \\
\hline 11 & 21 & $\mathrm{M}$ & $\mathbf{R h}$ & 一 & 60 & 20 & - \\
\hline 12 & 48 & $\mathbf{M}$ & $\mathbf{R h}$ & 一 & 94 & 30 & $\mathbf{R}+\mathbf{L}$ \\
\hline 13 & 33 & $\mathrm{M}$ & $?$ & 一 & 74 & 33 & 一 \\
\hline 14 & 19 & $\mathbf{M}$ & $?$ & 一 & 95 & 20 & 一 \\
\hline 15 & 36 & $\mathbf{M}$ & $\mathrm{Rh}$ & - & 66 & 32 & $\mathbf{R}+\mathbf{L}$ \\
\hline 16 & 35 & $\mathbf{M}$ & $R h$ & MVR & 126 & 32 & - \\
\hline 17 & 23 & $\mathbf{M}$ & $\mathbf{R h}$ & MVR & 197 & 34 & $\mathbf{R}+\mathbf{L}$ \\
\hline 18 & 18 & $\mathbf{M}$ & Rh & MVR & 120 & 30 & $\mathbf{R}+\mathbf{L}$ \\
\hline 19 & 54 & $\mathbf{M}$ & Cong & - & 114 & 30 & $\mathbf{R}+\mathbf{L}$ \\
\hline 20 & 28 & $\mathrm{~F}$ & Cong & - & 70 & 34 & $\mathbf{R}+\overline{\mathbf{L}}$ \\
\hline
\end{tabular}

Abbreviations : Cong, congenital bicuspid valve; $\mathrm{Rh}$, rheumatic; $\mathrm{R}+\mathrm{L}$, right and left coronary perfusion; $\mathrm{MVR}$, mitral valve replacement.

graphically at a paper speed of $100 \mathrm{~mm} / \mathrm{s}$, and a simultaneous electrocardiogram was obtained (Fig. 1).

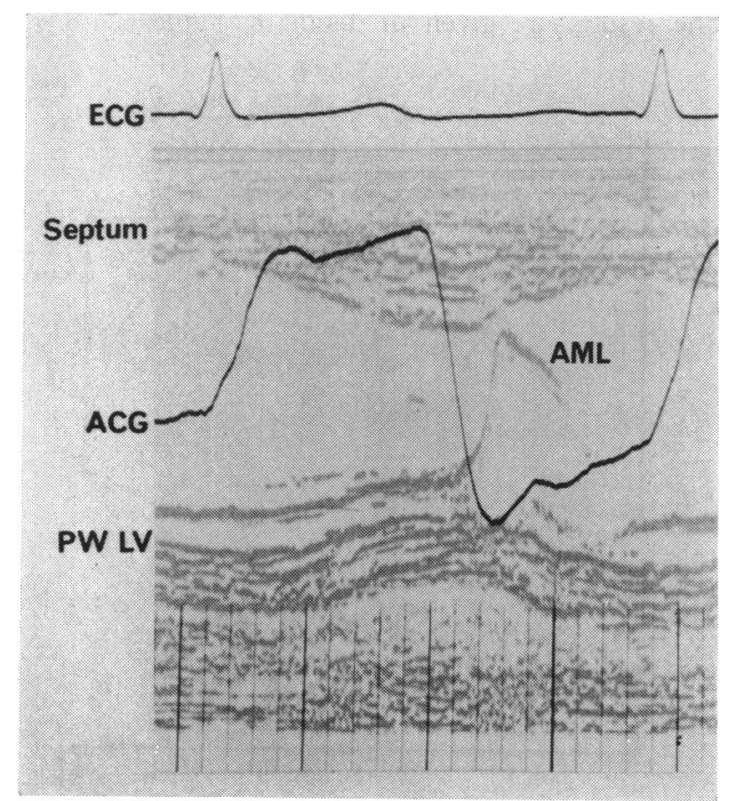

FIG. 1 Simultaneous apex and echocardiograms from a patient with aortic regurgitation. $P W=$ posterior left ventricular wall endocardium, $A M L=$ anterior mitral valve leaflet.

\section{Digitization}

Echocardiograms and apex cardiograms were digitized as previously described (Gibson and Brown, 1973), using a Summagraphics digitizer and a Prime 300 computer system. Data points were generated for the endocardium of the septum and posterior wall and for the apex cardiogram, together with calibration points defining a time interval of $0.5 \mathrm{~s}, 1 \mathrm{~cm}$ depth and two successive $Q$ waves on the electrocardiogram spanning the beat to be studied. From this information, 129 interpolated data points were derived, and the information stored for subsequent calculations. Using an incremental plotter, plots were made of left ventricular dimension, its rate of change, expressed both in $\mathrm{cm} / \mathrm{s}$ and in normalized form, and an apex cardiogram-echo dimension loop (Fig. 2).

Since the apex cardiogram is closely related to the left ventricular pressure pulse in time (Manolas et al., 1975; Venco, Gibson, and Brown, unpublished), the interval from the onset of the upstroke to the ' $E$ ' point represents the period of isovolumic contraction. Normally, either no change or a small decrease (mean $6.2 \pm 4.9 \%$ ) in dimension occurs during this period: a larger decrease or outward wall movement thus represents an abnormal isovolumic shape change. Early relaxation was studied in a similar manner, and was taken as the interval between the 'knee' of the apex cardiogram occurring at the end of ejection and the ' $O$ ' point. Previous studies have shown the knee to correspond to the onset of the closing movement of 

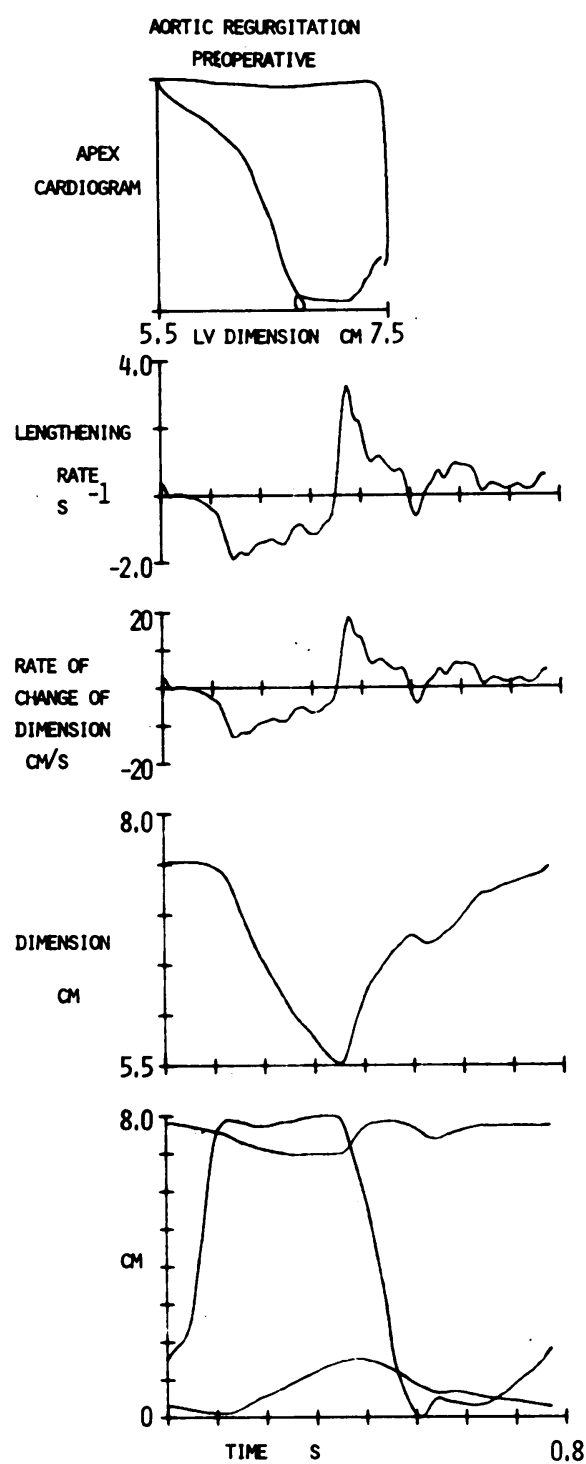

FIG. 2 Computer output of preoperative record of Case 9. The lowest trace represents the digitized apex and echocardiograms, and above are plots of left ventricular dimension $(D)$, rate of change of dimension $(d D / d t)$, normalized rate of change of dimension $(1 / D . d D / d t)$, and the echo dimension-apex cardiogram loop. Outward movement of the left ventricular walls during the downstroke of the apex cardiogram is apparent.

the aortic valve cusps and the ' $O$ ' point to be synchronous with the timing of peak rate of outward wall movement, thus following mitral valve opening by a short interval. Normally, $21 \pm 6 \cdot 8$ per cent of total diastolic excursion of wall movement occurs during this period. In order to quantify changes occurring during the periods of isovolumic contraction and early relaxation, the corresponding areas of the apex dimension loop were also measured. The loop itself was displayed on a Tektronix 4010 VDU using GINO-F display programmes, and the point corresponding to the onset of the upstroke, the ' $E$ ' point, the 'knee', and the ' $O$ ' point were identified with a cursor (Fig. 3). The two areas thus defined, together with that of the loop, were calculated by numerical integration, and normalized to a total value of 100 per cent.

End-diastolic dimension was taken as that synchronous with the QRS complex of the electrocardiogram, and end-systolic dimension as the minimum of the left ventricular dimension curve. Peak systolic and diastolic rates of wall movement were estimated in $\mathrm{cm} / \mathrm{s}$ and normalized form. From the apex dimension loop, the extent of inward or outward movement during the upstroke or downstroke of the apex cardiogram were measured directly, and the corresponding areas were defined as described above, and expressed as a percentage of the total.

\section{Results}

The results are given in detail in Tables 2 to 4 .

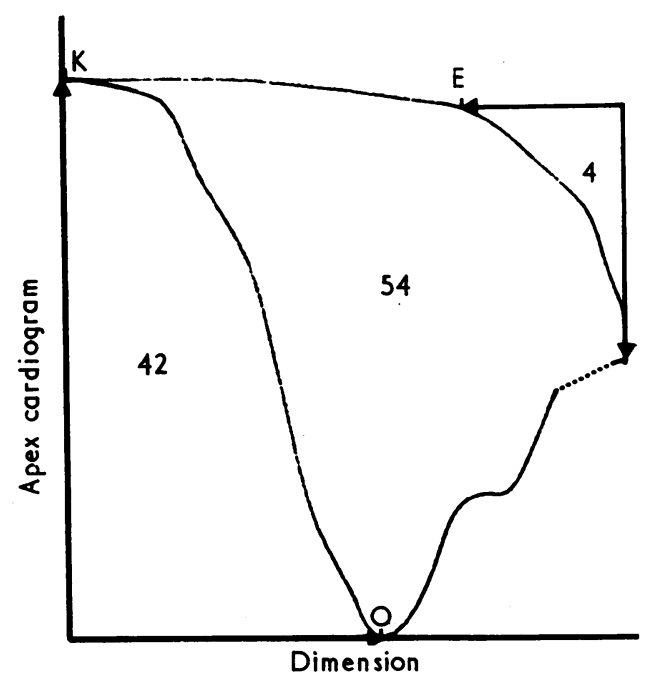

FIG. 3 Echo dimension-apex cardiogram loop showing measurements of area, expressed as a percentage of the whole. The $E$ point (E), 'Knee' (K), and ' $O$ ' point $(O)$ are indicated. 
TABLE 2 Changes in $L V$ dimension

\begin{tabular}{|c|c|c|c|c|c|c|c|c|c|c|c|c|c|c|c|c|}
\hline \multirow{2}{*}{$\begin{array}{l}\text { Case } \\
\text { No. }\end{array}$} & \multicolumn{4}{|c|}{ End-diastolic dimension $(\mathrm{cm})$} & \multicolumn{4}{|c|}{ End-systolic dimension (cm) } & \multicolumn{4}{|c|}{ Peak shortening rate $\left(\mathrm{s}^{-1}\right)$} & \multicolumn{4}{|c|}{ Peak lengthening rate $\left(s^{-1}\right)$} \\
\hline & Preop & $\begin{array}{l}1-3 \\
\text { days }\end{array}$ & $\begin{array}{l}5-6 \\
\text { days }\end{array}$ & $\begin{array}{l}8-10 \\
\text { days }\end{array}$ & Preop & $\begin{array}{l}1-3 \\
\text { days }\end{array}$ & $\begin{array}{l}5-6 \\
\text { days }\end{array}$ & $\begin{array}{l}8-10 \\
\text { days }\end{array}$ & Preop & $\begin{array}{l}1-3 \\
\text { days }\end{array}$ & $\begin{array}{l}5-6 \\
\text { days }\end{array}$ & $\begin{array}{l}8-10 \\
\text { days }\end{array}$ & Preop & $\begin{array}{l}1-3 \\
\text { days }\end{array}$ & $\begin{array}{l}5-6 \\
\text { days }\end{array}$ & $\begin{array}{l}8-10 \\
\text { days }\end{array}$ \\
\hline 1 & $7 \cdot 8$ & & $6 \cdot 5$ & $5 \cdot 5$ & $5 \cdot 9$ & & $5 \cdot 1$ & $4 \cdot 1$ & $2 \cdot 0$ & & $1 \cdot 7$ & $1 \cdot 8$ & 1.5 & & $2 \cdot 2$ & $3 \cdot 2$ \\
\hline 2 & $5 \cdot 5$ & $4 \cdot 4$ & & 4.5 & 3.6 & 3.6 & & $3 \cdot 8$ & $2 \cdot 0$ & $1 \cdot 4$ & & $1 \cdot 4$ & $2 \cdot 8$ & $2 \cdot 6$ & & $1 \cdot 0$ \\
\hline 3 & $7 \cdot 3$ & $7 \cdot 2$ & $7 \cdot 1$ & & $6 \cdot 0$ & $6 \cdot 4$ & $6 \cdot 4$ & & $1 \cdot 3$ & $1 \cdot 0$ & $0 \cdot 8$ & & $2 \cdot 9$ & $2 \cdot 2$ & $1 \cdot 7$ & \\
\hline 4 & 5.9 & 4.5 & & & 3.5 & 3.4 & & & 1.2 & $2 \cdot 0$ & & & $5 \cdot 0$ & $4 \cdot 0$ & & \\
\hline 5 & $7 \cdot 7$ & & $6 \cdot 2$ & & $4 \cdot 8$ & & $4 \cdot 6$ & & $2 \cdot 4$ & & $1 \cdot 5$ & & $4 \cdot 4$ & & $2 \cdot 4$ & \\
\hline 6 & 6.5 & & $5 \cdot 5$ & & $4 \cdot 6$ & & $4 \cdot 6$ & & 1.7 & & $1 \cdot 3$ & & $2 \cdot 0$ & & $2 \cdot 0$ & \\
\hline 7 & $6 \cdot 6$ & & $4 \cdot 6$ & & $4 \cdot 3$ & & 3.9 & & $3 \cdot 0$ & & $2 \cdot 2$ & & $2 \cdot 6$ & & $3 \cdot 0$ & \\
\hline 8 & $7 \cdot 0$ & & $6 \cdot 1$ & & $5 \cdot 1$ & & $5 \cdot 3$ & & $1 \cdot 7$ & & $1 \cdot 3$ & & 1.9 & & 1.9 & \\
\hline 9 & $7 \cdot 5$ & $4 \cdot 3$ & & $5 \cdot 0$ & $5 \cdot 5$ & 3.5 & & $4 \cdot 1$ & $2 \cdot 0$ & 1.5 & & 1.4 & 3.3 & $2 \cdot 5$ & & $2 \cdot 0$ \\
\hline 10 & $6 \cdot 1$ & & $5 \cdot 6$ & & 4.5 & & $4 \cdot 6$ & & $1 \cdot 2$ & & $1 \cdot 2$ & & 1.4 & & $1 \cdot 7$ & \\
\hline 11 & 6.9 & & $6 \cdot 4$ & & $4 \cdot 5$ & & $5 \cdot 5$ & & $2 \cdot 5$ & & $1 \cdot 2$ & & 3.9 & & $1 \cdot 2$ & \\
\hline 12 & $6 \cdot 6$ & & 4.9 & & $5 \cdot 3$ & & & 3.8 & 1.8 & & & $1 \cdot 8$ & 1.9 & & & $2 \cdot 4$ \\
\hline 13 & 8.0 & $7 \cdot 2$ & 7.5 & & $5 \cdot 5$ & 6.5 & 5.9 & & 1.5 & 0.8 & $1 \cdot 3$ & & $4 \cdot 6$ & $1 \cdot 2$ & $1 \cdot 7$ & \\
\hline 14 & $7 \cdot 0$ & $6 \cdot 1$ & & $5 \cdot 6$ & $4 \cdot 1$ & $5 \cdot 4$ & & $4 \cdot 7$ & 2.5 & $1 \cdot 2$ & & 1.2 & $5 \cdot 2$ & 0.8 & & 1.6 \\
\hline 15 & 7.9 & & $7 \cdot 7$ & 6.9 & 6.5 & & 6.9 & 6.0 & 1.5 & & 0.8 & 1.5 & $1 \cdot 8$ & & 1.2 & $1 \cdot 8$ \\
\hline 16 & 5.9 & & & 4.9 & $4 \cdot 6$ & & 3.5 & & 1.4 & & $2 \cdot 2$ & & $2 \cdot 6$ & & $5 \cdot 0$ & \\
\hline 17 & $7 \cdot 2$ & & $6 \cdot 8$ & & $5 \cdot 8$ & & 6.0 & & $1 \cdot 7$ & & 0.7 & & 2.9 & & $2 \cdot 0$ & \\
\hline 18 & 8.0 & $6 \cdot 3$ & $6 \cdot 3$ & & $5 \cdot 4$ & $5 \cdot 5$ & $5 \cdot 1$ & & $2 \cdot 4$ & 1.0 & 1.5 & & $4 \cdot 8$ & 1.5 & $1 \cdot 4$ & \\
\hline 19 & $9 \cdot 0$ & & $7 \cdot 4$ & & 7.9 & & $6 \cdot 7$ & & 0.9 & & 0.7 & & 0.8 & & $1 \cdot 3$ & \\
\hline 20 & 6.8 & & & 4.0 & 3.9 & & & 3.3 & $3 \cdot 1$ & & & 1.6 & 6.8 & & & $3 \cdot 1$ \\
\hline
\end{tabular}

\section{Left ventricular dimension}

The mean end-systolic dimension was $5.0 \pm 1.0 \mathrm{~cm}$ before and $4.7 \pm 1.0 \mathrm{~cm}$ after operation, which was not significantly different. There was, however, a highly significant drop in end-diastolic dimension from $7.0 \pm 0.8 \mathrm{~cm}$ to $5.7 \pm 1.0 \mathrm{~cm} 7$ days after operation $(P<0.001)$. If the 7 patients are considered in whom multiple estimations were performed, it is apparent that this reduction in diastolic dimension occurred very early in the postoperative period, being already significant 2 days after valve replacement $(P<0 \cdot 01)$. A further slight reduction took place between the second and the ninth postoperative day, but this was not statistically significant. Of the patients in whom the reduction in enddiastolic diameter was less than $0.5 \mathrm{~cm}, 1$ had a para-

TABLE 3 Changes in echo dimension-apex cardiogram loop

\begin{tabular}{|c|c|c|c|c|c|c|c|c|c|c|c|c|}
\hline \multirow{2}{*}{$\begin{array}{l}\text { Case } \\
\text { No. }\end{array}$} & \multicolumn{4}{|c|}{ Total area (\%) (within loop) } & \multicolumn{4}{|c|}{ Change before ' $E$ ' point (\%) } & \multicolumn{4}{|c|}{ Change before ' $O$ ' point (\%) } \\
\hline & Preop & $\begin{array}{l}1-3 \\
\text { days }\end{array}$ & $\begin{array}{l}5-6 \\
\text { days }\end{array}$ & $\begin{array}{l}8-10 \\
\text { days }\end{array}$ & Preop & $\begin{array}{l}1-3 \\
\text { days }\end{array}$ & $\begin{array}{l}5-6 \\
\text { days }\end{array}$ & $\begin{array}{l}8-10 \\
\text { days }\end{array}$ & Preop & $\begin{array}{l}1-3 \\
\text { days }\end{array}$ & $\begin{array}{l}5-6 \\
\text { days }\end{array}$ & $\begin{array}{l}8-10 \\
\text { days }\end{array}$ \\
\hline 1 & 52 & & 31 & 28 & 7 & & 26 & 39 & 41 & & 45 & 33 \\
\hline 2 & 83 & 53 & & 92 & 11 & 11 & 3 & & 6 & 36 & & 5 \\
\hline 3 & 71 & 76 & 62 & & 3 & 5 & 3 & & 26 & 18 & 35 & \\
\hline 4 & 92 & 84 & & & 1 & 9 & & & 6 & 8 & & \\
\hline 5 & 76 & & 57 & & 7 & & 29 & & 17 & & 14 & \\
\hline 6 & 82 & & 66 & & 6 & & 5 & & 12 & & 29 & \\
\hline 7 & 85 & & 86 & & 5 & & 12 & & 10 & & 5 & \\
\hline 8 & 79 & & 67 & & 7 & & 16 & & 15 & & 24 & \\
\hline 9 & 57 & 58 & & 80 & 1 & 14 & & 13 & 42 & 28 & & 7 \\
\hline 10 & 78 & & 57 & & 13 & & 16 & & 7 & & 27 & \\
\hline 11 & 97 & & 81 & & 2 & & 6 & & 1 & & 12 & \\
\hline 12 & 73 & & & 87 & 1 & & & 1 & 26 & & & 12 \\
\hline 13 & 75 & 66 & 81 & & 2 & 5 & 4 & & 23 & 27 & 15 & \\
\hline 14 & 92 & 48 & & 75 & 4 & 15 & & 6 & 3 & 36 & & 19 \\
\hline 15 & 76 & & 59 & 53 & $i$ & & 13 & 9 & 24 & & 29 & 38 \\
\hline 16 & 82 & & 89 & & 3 & & 4 & & 16 & & 6 & \\
\hline 17 & 77 & & 58 & & 6 & & 30 & & 17 & & 30 & \\
\hline 18 & 91 & 73 & 56 & & 6 & 14 & 5 & & 1 & 13 & 38 & \\
\hline 19 & 64 & & 48 & & 2 & & 42 & & 34 & & 10 & \\
\hline 20 & 65 & & & 86 & 25 & & & 4 & 10 & & & 10 \\
\hline
\end{tabular}


TABLE 4A Paired $t$ test between determinations before and after aortic valve replacement in 20 patients

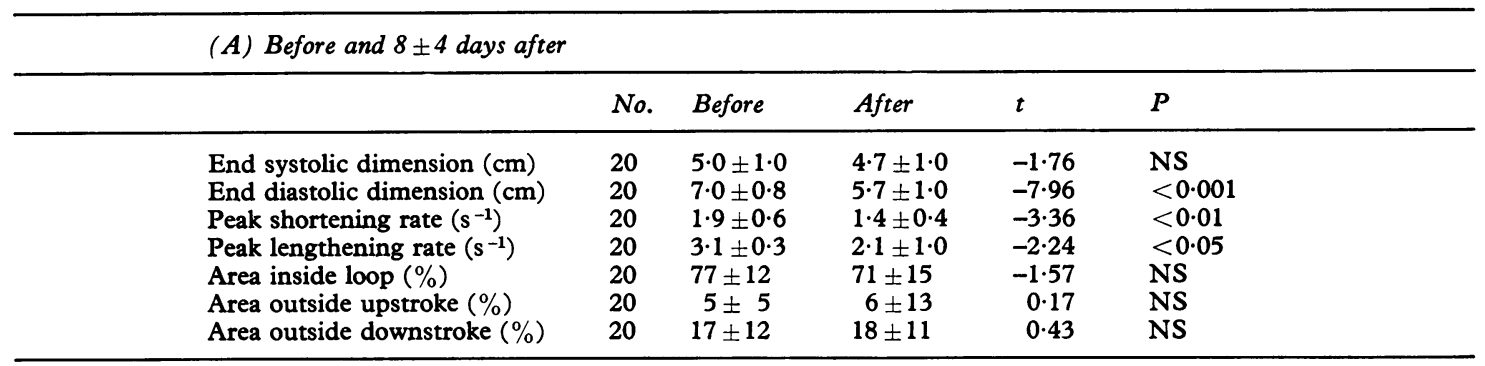

Mean \pm standard deviation; NS $=$ Not significant.

TABLE 4B Paired $t$ test showing sequential changes in 7 patients

\begin{tabular}{|c|c|c|c|c|}
\hline & No. & Mean difference & $t$ & $P$ \\
\hline \multicolumn{5}{|c|}{ Comparison between preoperative and $2 \pm 1$ days after } \\
\hline $\begin{array}{l}\text { End systolic dimension }(\mathrm{cm}) \\
\text { End diastolic dimension }(\mathrm{cm}) \\
\text { Peak shortening rate }\left(\mathrm{s}^{-1}\right) \\
\text { Peak lengthening rate }\left(\mathrm{s}^{-1}\right) \\
\text { Area inside loop }(\%) \\
\text { Area outside upstroke }(\%) \\
\text { Area outside downstroke }(\%)\end{array}$ & $\begin{array}{l}7 \\
7 \\
7 \\
7 \\
7 \\
7 \\
7\end{array}$ & $\begin{array}{r}0.05 \\
-1 \cdot 16 \\
-0.72 \\
-0.15 \\
-21 \cdot 88 \\
8 \cdot 88 \\
12 \cdot 75\end{array}$ & $\begin{array}{r}0 \cdot 14 \\
-3 \cdot 36 \\
-4 \cdot 92 \\
-2 \cdot 44 \\
-2 \cdot 82 \\
3 \cdot 74 \\
1 \cdot 80\end{array}$ & $\begin{array}{l}\text { NS } \\
<0.01 \\
<0.01 \\
<0.05 \\
<0.05 \\
<0.01 \\
\text { NS }\end{array}$ \\
\hline \multicolumn{5}{|c|}{ Comparison between $2 \pm 1$ days after and $7 \pm 3$ days after } \\
\hline $\begin{array}{l}\text { End systolic dimension }(\mathrm{cm}) \\
\text { End diastolic dimension }(\mathrm{cm}) \\
\text { Peak shortening rate }\left(\mathrm{s}^{-1}\right) \\
\text { Peak lengthening rate }\left(\mathrm{s}^{-1}\right) \\
\text { Area inside loop }(\%) \\
\text { Area outside upstroke }(\%) \\
\text { Area outside downstroke }(\%)\end{array}$ & $\begin{array}{l}7 \\
7 \\
7 \\
7 \\
7 \\
7 \\
7\end{array}$ & $\begin{array}{r}-0.35 \\
-0.16 \\
0.16 \\
0.02 \\
18.75 \\
-10.88 \\
-10.75\end{array}$ & $\begin{array}{r}-1 \cdot 75 \\
-0 \cdot 81 \\
1 \cdot 27 \\
0 \cdot 08 \\
2 \cdot 31 \\
-3 \cdot 41 \\
-1 \cdot 48\end{array}$ & $\begin{array}{l}\text { NS } \\
\text { NS } \\
\text { NS } \\
\text { NS } \\
<0.05 \\
<0.01 \\
\text { NS }\end{array}$ \\
\hline
\end{tabular}

prosthetic leak, 2 developed low output states, and 1 had clear evidence of left ventricular disease preoperatively on the basis of a low ejection fraction and a reduced value of peak normalized shortening rate.

\section{Peak rates of wall movement}

The mean values of peak normalized rates of wall movement, both in systole and diastole, were significantly reduced after operation $(P<0.01$ and $\mathbf{P}<0.05$, respectively). This reduction was also apparent in the very early postoperative period, with a slight, though statistically non-significant, increase thereafter. Changes in lengthening rate were noticeably less consistent than those in peak shortening rate (Table 4).

\section{Isovolumic contraction and early relaxation}

There was no significant change in the extent of inward wall movement during the period of isovolumic contraction or in the corresponding area when preoperative and the latest postoperative values were compared. However, early postoperative measurements showed a significant increase in inward wall movement during this period, which regressed over the succeeding 7 to 10 days. In spite of correction of the aortic regurgitation, outward wall movement during early relaxation persisted postoperatively, suggesting the development of additional abnormalities in this period of the cardiac cycle (Fig. 4 and 5). Both these changes resulted in a significant reduction of the area within the loop expressed as a percentage of the whole. These changes were more extensive in 2 patients whose 

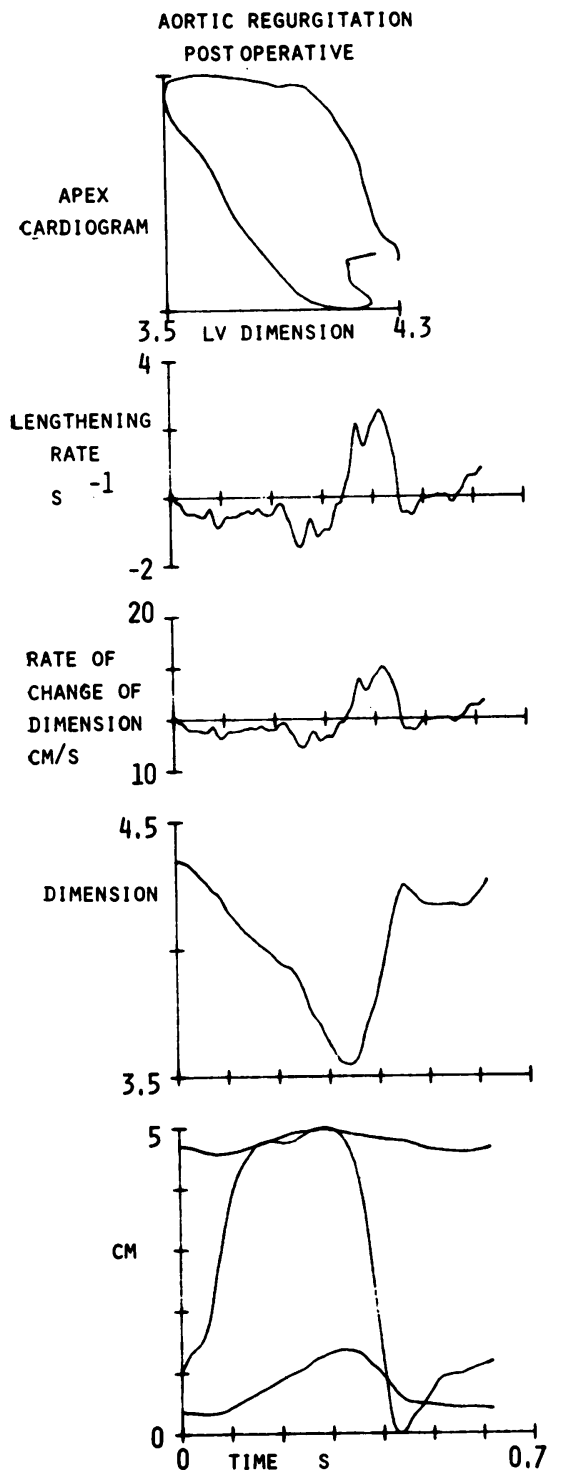

FI G. 4 Computer output from Case 9, 3 days postoperatively. The layout is the same as for Fig. 2. Abnormal wall movement during the upstroke of the apex cardiogram is now apparent.

postoperative course was complicated. In 1, a low cardiac output state persisted for 3 to 4 weeks, and throughout there was clear correlation between his clinical state and the configuration of the loop (Fig. 6). The second developed a paraprosthetic leak, and a distorted loop persisted until a second operation. Though all patients had reversed septal movement, this persisted unchanged while the loop improved. There was no correlation, in individual patients, between the duration of cardiopulmonary bypass and any feature of left ventricular function.

\section{Discussion}

Persistence of impaired left ventricular function has been reported in patients 1 month to 2 years after aortic valve replacement, but there is still little information about changes in the early postoperative
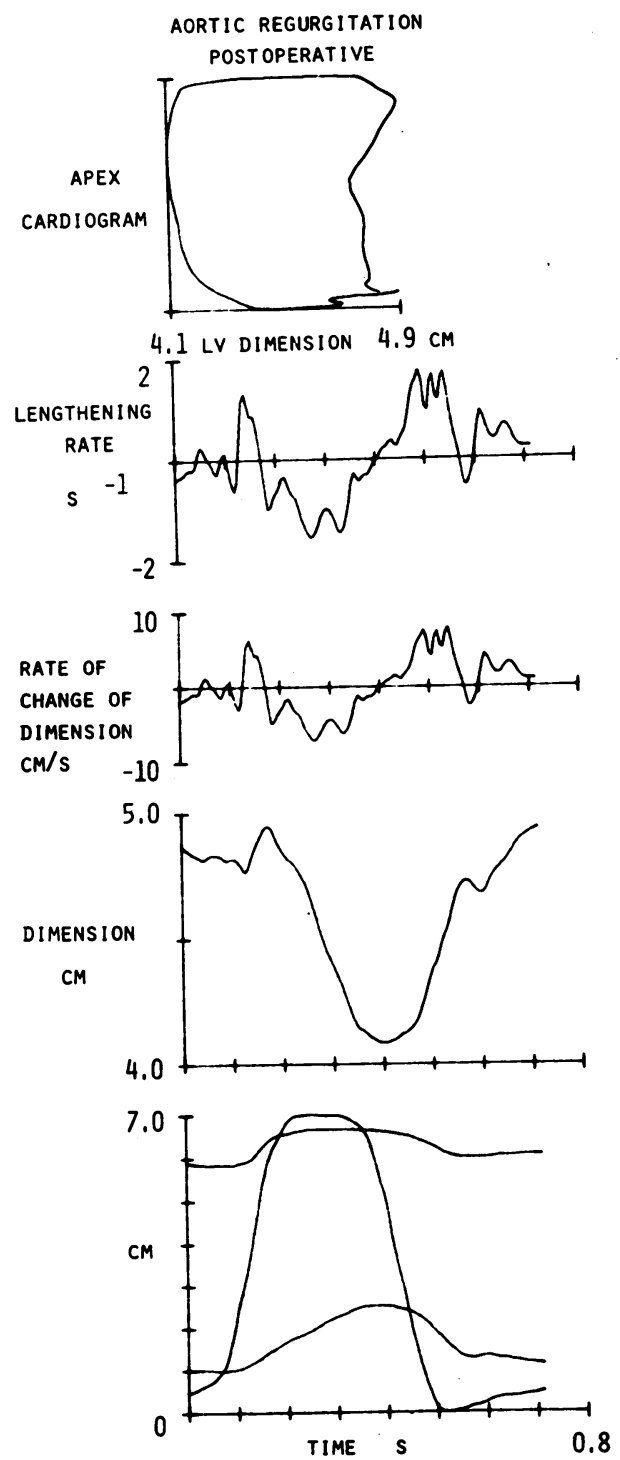

FIG. 5 Computer output from Case 9, 10 days after operation. There has been partial regression of the abnormalities present at 3 days. 


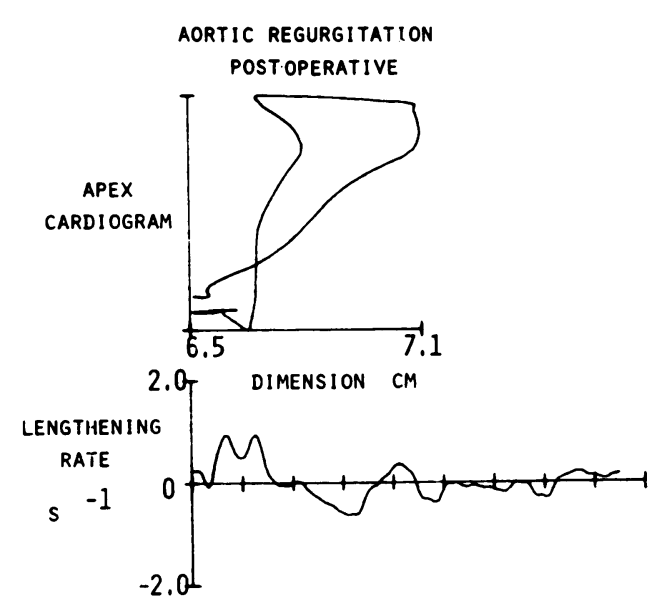

made by a number of authors (Carey and Plested, 1972; Uhrenholdt et al., 1973), but these may be difficult to interpret: cardiac output or enddiastolic pressure may be affected by transfusion, catecholamine infusion, or pericardial pressure and cannot therefore be taken as directly reflecting the function of the left ventricle. Estimation of systolic time intervals is non-specific and subject to limitations in the postoperative period, particularly when comparison is made with values from normal controls, and when they are dependent on the timing of aortic valve closure, which may be modified by the presence of a prosthetic valve. We have, therefore, based the present study on simultaneous apex and echocardiograms, both of which were relatively easy to perform in the early postoperative period in the patient group studied. The echocardiogram gave information about left ventricular cavity size, peak rates of wall movement, and also the direction of septal movement. With additional information available from the apex cardiogram, it was possible to detect and quantify abnormal wall movement occurring during isovolumic contraction and the period of early relaxation, which have previously been shown to be associated with overall impairment of the function of the left ventricle.

The present study indicated changes in three aspects of left ventricular function apparent in the early postoperative period; reduction in enddiastolic diameter, a drop in peak normalized shortening rate, and abnormalities of wall movement during the early phases of contraction and relaxation. All these changes were apparent within the first 2 days after operation: those in dimension and peak rate of change of dimension persisted virtually unchanged until the end of the study, while those associated with abnormalities of the apex dimension loop tended to regress. The changes in dimension and peak normalized shortening rate are similar to those described by other authors (Gault et al., 1970; Burggraf and Craige, 1975) after longer periods following operation. McDonald (1972), however, had already noted that impairment of shortening of myocardial fibres alone would not explain his observations on the movement of epicardial clips. He noted, in particular, the tendency for base to apex shortening to be more impaired than that along the minor diameter, and suggested the possibility of an underlying change in ventricular architecture. In addition, he observed the presence of reduced shortening or even lengthening of some segments during isovolumic contraction, and during ejection similar abnormalities or premature cessation of shortening occurred. Our findings are compatible with these observations, suggesting that such incoordinate

period. This may be related to technical difficulties in making the appropriate measurements. Angiocardiographic techniques do not lend themselves to repeated performance, and in any case, are not feasible immediately after open-heart surgery. Standard haemodynamic measurements have been 
contraction may appear in the early postoperative period, with only partial regression thereafter. If incoordinate left ventricular contraction is indeed a significant aspect of postoperative left ventricular disorder, this finding may have therapeutic implications, since treatment with positive inotropic drugs would not necessarily be expected to have the same beneficial effect as if impaired cardiac function were the result of a uniform depression of contractile state.

The present results also stress difficulties in attempting to quantify left ventricular function in terms of a single 'index' or 'parameter', when a number of separate changes are occurring simultaneously. In the immediate postoperative period, end-diastolic dimension was reduced, suggesting an improvement, while peak shortening rate dropped, indicating a deterioration in left ventricular performance. At the same time, there was evidence of incoordinate left ventricular contraction which was most striking 4 to 5 days after operation and then regressed, while the other variables remained unchanged. It is difficult to see how these changes could have been expressed in terms of a single quantity, however specific or sensitive it may have been. Rather, it is suggested that, in clinical practice, impaired left ventricular function may result from a number of different disturbances. The present study indicates that an initial analysis may usefully be made in terms of changes in ventricular dimension, peak rates of wall movement and contraction pattern, and suggests a non-invasive approach to the problem.
The computer equipment used for this study was provided by the DHSS as part of their experimental computer programme.

\section{References}

Burggraf, G. W., and Craige, E. (1975). Echocardiographic studies of left ventricular wall motion and dimensions after valvular heart surgery. American fournal of Cardiology, 35, 473.

Carey, J. S., and Plested, W. G. (1972). Immediate haemody namic response to correction of cardiac valvular lesions. Annals of Thoracic Surgery, 13, 311.

Gault, J. H., Covell, J. W., Braunwald, E., and Ross, J., Jr. (1970). Left ventricular performance following correction of free aortic regurgitation. Circulation, 42, 773.

Gibson, D. G., and Brown, D. (1973). Measurement of instantaneous left ventricular dimension and filling rate in man, using echocardiography. British Heart fournal, 35, 1141.

McDonald, I. G. (1972). Contraction of the hypertrophied left ventricle in man studied by cineradiography of epicardial markers. American fournal of Cardiology, 30, 587.

Manolas, J., Rutishauser, W., Wirz, P., and Arbenz, U. (1975). Time relation between apex cardiogram and left ventricular events, using simultaneous high-fidelity tracings in man. British Heart fournal, 37, 1263.

Seabra-Gomez, R., Sutton, R., and Parker, J. (1974). Left ventricular function after aortic valve replacement (abstract). British Heart Fournal, 36, 403.

Uhrenholdt, A., Henningsen, P., Rygg, I. H., and Lauridsen, P. (1973). Pre- and post-operative clinical and haemodynamic results after prosthetic replacement of cardiac valves. Scandinavian fournal of Thoracic and Cardiovascular Surgery, 7, 31.

Requests for reprints to Dr. D. G. Gibson, Department of Cardiology, Brompton Hospital, Fulham Road, London SW3 6HP. 